\title{
Percutaneous Nephrolithotomy Induced Renal Hemorrhage in a Patient with Bilateral Double Renal Arteries: A Case Report and Literature Review
}

\author{
Song Wen, Meifang Li, Laishu Luo, Xiaoming Hu, Youmei Zhang, Ping Chen* \\ Interventional Room of Oncology, Second Affiliated Hospital, Nanchang University, Nanchang, China \\ Email: ${ }^{*}$ drchenping@163.com
}

Received 5 October 2014; revised 5 November 2014; accepted 25 November 2014

Copyright (C) 2014 by authors and Scientific Research Publishing Inc.

This work is licensed under the Creative Commons Attribution International License (CC BY). http://creativecommons.org/licenses/by/4.0/

(c) (i) Open Access

\begin{abstract}
Percutaneous nephrolithotomy is a minimal invasive important technique for stones of the renal pelvis. However, severe hemorrhage after percutaneous nephrolithotomy is a rare but life-threatening event. Bilateral double renal arteries are kind of relatively infrequent renal vascular variation. Here, we reported a rare case of percutaneous nephrolithotomy induced renal hemorrhage in a patient with bilateral double renal arteries, and our experience of successful rescue in this patient.
\end{abstract}

\section{Keywords}

Hemorrhage, Interventional, Percutaneous Nephrolithotomy

\section{Introduction}

Percutaneous nephrolithotomy (PCNL) represents a minimal invasive procedure in the surgical management of renal stone with a diameter less than $2 \mathrm{~cm}$ [1]. Although this technique is safe and effective, complications, including hemorrhages, have been reported and become a severe cause of patient morbidity [2]. Super-selective renal artery embolization (SRAE) of the injured vessel is an effective, minimally invasive and relatively easy procedure in experienced centers, with high rate of success and immediate benefits, thus saving the patient from the morbidity those results from severe renal bleeding [3]. Bilateral double renal arteries are a seldom renal vascular variation, which occur in $10 \%-15 \%$ of the population [4]. Here, we reported a rare case of percutane-

\footnotetext{
*Corresponding author.
}

How to cite this paper: Wen, S., Li, M.F., Luo, L.S., Hu, X.M., Zhang, Y.M. and Chen, P. (2014) Percutaneous Nephrolithotomy Induced Renal Hemorrhage in a Patient with Bilateral Double Renal Arteries: A Case Report and Literature Review. Open Journal of Clinical Diagnostics, 4, 247-250. http://dx.doi.org/10.4236/ojcd.2014.44035 
ous renal hemorrhage in a patient with bilateral double renal arteries and successful rescue in this patient. Furthermore, written informed consent was obtained from the patient.

\section{Case Presentation}

A 51-year male was found having recurrent gross hematuria 12 days after ultrasound-guided percutaneous nephrolithotomy (PCNL) due to right renal stone and giant hydronephrosis at other hospital. Recurrent gross hematuria with blood clots were seen after PCNL and these symptoms were slightly relieved through appropriate treatment, such as complete rest in bed, injection hemostasis, red cells transfusion and kidney fistula occlusion. Obvious gross hematuria and blood clots were seen again 2 days after pull out of fistula (one week post-operation) accompany with obstruction of urethral catheter although several bladder irrigation. Because of pain and discomfort within bladder area, the patient was transferred to our hospital for further treatment. Patient felt loss of appetite, poor sleep; weight decreased slightly since the onset, but had any of the following symptoms: fever, joint pain, melena, headache, dizziness, chest tightness, palpitation. Physical examination when hospitalized did not find anything abnormal in his lung, heart and limbs. Body temperature $36.8^{\circ} \mathrm{C}$, pulse 85 beats/min, respiratory 20 beats/min, blood pressure 130/80 mmHg. Blood test: RBC (red blood cell) $2.85 \times 10^{12} / \mathrm{L}$, WBC (white blood cell) $7.17 \times 10^{9} / \mathrm{L}$, hemoglobin $91 \mathrm{~g} / \mathrm{L}$. BUN (blood urea nitrogen) $7.40 \mathrm{mmol} / \mathrm{L}$, serum creatinine 142.5 $\mu \mathrm{mol} / \mathrm{L}$. The results from all the following tests were normal: bleeding time, blood coagulation time, plasmic electrolytes. CT examination showed the irregular contours of right kidney without hemorrhage around (Figure 1(A)). A lot of blood blots in right renal pelvis, right ureter and bladder (Figure 1(B)).

After informed consent was obtained from the patient and his immediate family members, digital subtraction angiography (DSA, OEC9800 C-arm X-ray system, GE, USA) of bilateral renal arteries was performed through right femoral artery using a 6F, 40-cm Flexor Check-Flo sheath and 5F Cobra catheter (Cook Medical, Bloomington, IN). For the first subtraction angiography of right renal artery, no signs of renal artery renal hemorrhage were found and the renal artery system seems intact for the right renal (Figure 2(A)). However, an obvious severe bleeding from the inferior right accessory renal artery at the lower pole of the right renal was found (Figure 2(B)). After the application of the accessory renal artery embolization with gelatin sponge particles and two fibered platinum coils, bleeding was stopped indicated by subtraction angiography (Figure 2(C)) and hemoglobin returned to normal in 7 days after surgery. Furthermore, the DSA images showed that the left renal has also double renal arteries origin from the descending aorta (Figure 3(A) and Figure 3(B)).

\section{Discussion}

Percutaneous nephrolithotomy (PCNL) is a well-established minimally invasive treatment modality for stones of the renal pelvis, either as monotherapy or in combination with extracorporeal shockwave lithotripsy (ESWL). As reported, the complete and relative success rates of PCNL were $89.4 \%$ and $10.6 \%$ [1], which provides overall significantly higher stone-free rates than retrograde intrarenal surgery (weighted mean difference: 2.19; 95\%
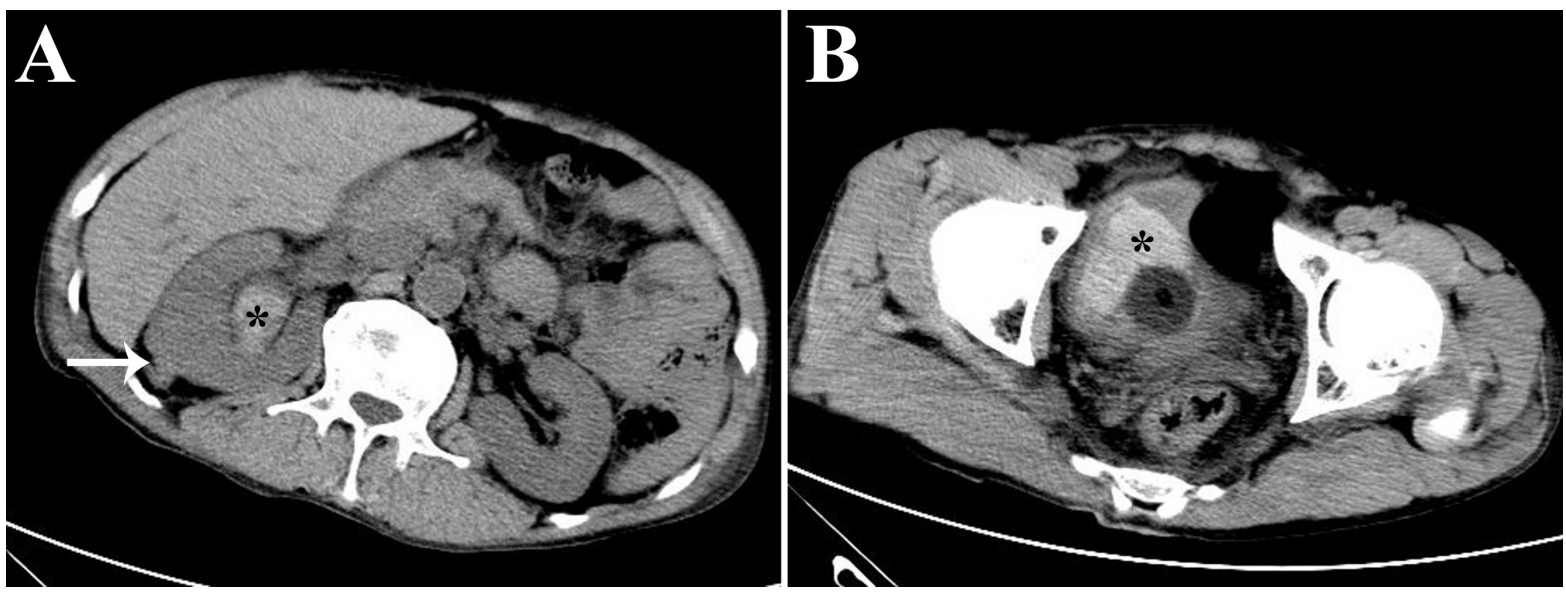

Figure 1. Abdominal CT images. CT images showed the irregular contours of right kidney (white arrow, (A)), blood blot in right renal pelvis (black asterisk, (A)) and bladder (black asterisk, (B)). 

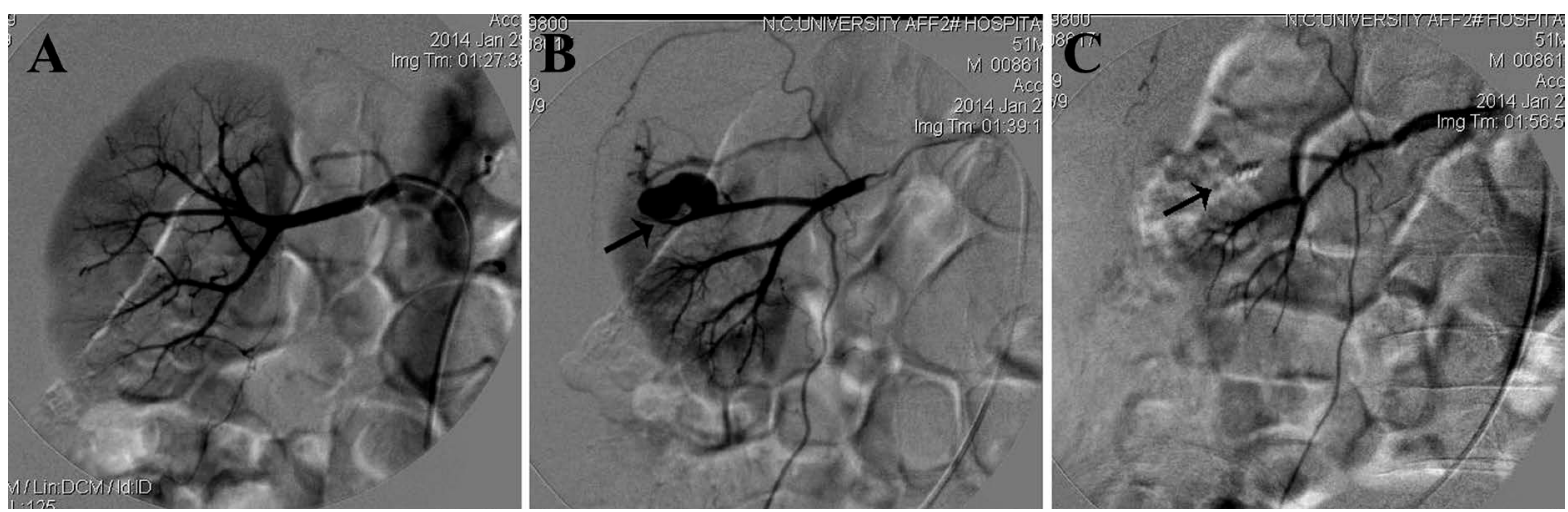

Figure 2. Images from right renal arteriography. (A) Without renal blood flow of right renal in the first DSA image; (B) The arrow points to an accessory renal artery from abdominal aorta with bleeding in the lower pole of right kidney; (C) The right accessory renal arterial bleeding stopped after vascular embolization with gelatin sponge particles and fibered platinum coils (arrow).
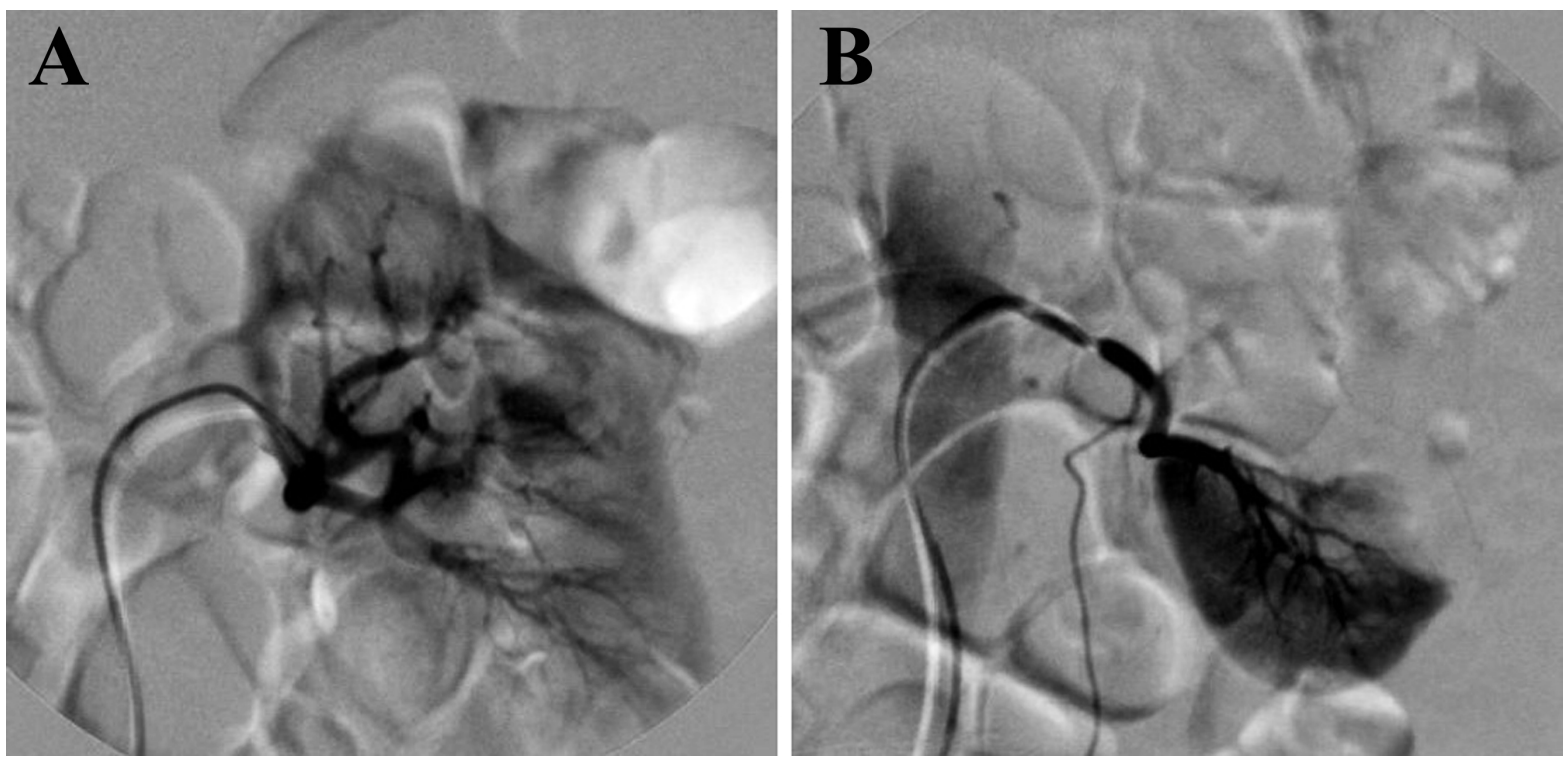

Figure 3. Images from left renal arteriography. DSA images of left renal show that the upper left renal artery (A) and bottom left renal artery (B) provides blood for upper pole and bottom pole of left renal, respectively.

confidence interval, 1.53 - 3.13) [5]. However, severe hemorrhage after percutaneous nephrolithotomy is a rare complication (less than 1\%) but life-threatening event [6]. Several risk factors, such as upper caliceal puncture, solitary kidney, staghorn stone, multiple punctures and inexperienced surgeon were associated with increased renal hemorrhage during PCNL [2]. If local tamponade fails to control bleeding, the current treatment of choice is SRAE [3] [7]. It is effective and minimal invasive for the control of renal hemorrhage with minimal morbidity and maximal renal function preservation [3]. Similar as other studies, our case proved that benefit effects of SRAE for post-PCNL renal vascular injuries are pronounced in patients. Our experience strongly recommended again that the first-line use of SRAE for severe renal hemorrhage post-PCNL.

An interest issue in this case is the anatomical variations of renal vascular. Although accessory renal arteries are the most common renal vascular variant and are seen in about one-third of the population, bilateral double renal arteries are seldom and can be detected through multidetector CT angiography, DSA and necropsy by chance [8] [9]. As Figure 3 demonstrated, most double renal arteries provides blood to different lobe of renal and "filling defect" sign was clearly in DSA images [10]. In the current case, "filling defect" sign is not available in the DSA image because the upper right renal artery provides blood for most of right renal. We have learned from this case that it necessary that find accessory renal artery to eliminated the possible of artery he- 
morrhage if the "filling defect" sign is not clear. Whole aortic DSA imaging by using a pigtail catheter before or after the super-selective renal artery DSA imaging may help to diagnosis the accessory renal artery bleeding, if it is not available for the sign of renal artery bleeding post-PCNL in the DSA procession. It is expected that our case will provide important insight for clinic interventional radiologist, particularly for early-career interventional radiologist in treatment of renal hemorrhage diseases.

In conclusion, we reported a rare case of PCNL induced right accessory renal artery hemorrhage in a patient with bilateral double renal arteries, and our experience of successful rescue in this patient. SRAE is an effective and minimal invasive method for the control of renal hemorrhage induced by PNCL. Future studies are needed to evaluate the necessity and significance of whole aortic DSA imaging for PCNL induced renal hemorrhage used in current case because of rare anatomical variations of renal arteries.

\section{Funding}

This work was supported by a grant from National Natural Science Foundation of China (\#81401460 and \#91029720).

\section{References}

[1] Mousavi-Bahar, S.H., Mehrabi, S. and Moslemi, M.K. (2011) The Safety and Efficacy of PCNL with Supracostal Approach in the Treatment of Renal Stones. International Urology and Nephrology, 43, 983-987. http://dx.doi.org/10.1007/s11255-011-9916-y

[2] Wang, Y., Jiang, F., Hou, Y., Zhang, H., Chen, Q., et al. (2012) Post-Percutaneous Nephrolithotomy Septic Shock and Severe Hemorrhage: A Study of Risk Factors. Urology International, 88, 307-310. http://dx.doi.org/10.1159/000336164

[3] Wang, C., Mao, Q., Tan, F. and Shen, B. (2014) Superselective Renal Artery Embolization in the Treatment of Renal Hemorrhage. Irish Journal of Medical Science, 183, 59-63. http://dx.doi.org/10.1007/s11845-013-0972-4

[4] Valastro, M., Veroux, M., Macarone, M., Cappello, D., Vizcarra, D., et al. (2007) Multi-Detector Row CT Scanner Angiography in the Evaluation of Living Kidney Donors. Chirurgia Italiana, 59, 337-341.

[5] Zheng, C., Xiong, B., Wang, H., Luo, J., Zhang, C., et al. (2014) Retrograde Intrarenal Surgery versus Percutaneous Nephrolithotomy for Treatment of Renal Stones $>2$ cm: A Meta-Analysis. Urology International. Urologia Internationalis. http://dx.doi.org/10.1159/000363509

[6] Rastinehad, A.R., Andonian, S., Smith, A.D. and Siegel, D.N. (2009) Management of Hemorrhagic Complications Associated with Percutaneous Nephrolithotomy. Journal of Endourology, 23, 1763-1767. http://dx.doi.org/10.1089/end.2009.1548

[7] Jain, V., Ganpule, A., Vyas, J., Muthu, V., Sabnis, R.B., et al. (2009) Management of Non-Neoplastic Renal Hemorrhage by Transarterial Embolization. Urology, 74, 522-526. http://dx.doi.org/10.1016/j.urology.2008.11.062

[8] Turkvatan, A., Ozdemir, M., Cumhur, T. and Olcer, T. (2009) Multidetector CT Angiography of Renal Vasculature: Normal Anatomy and Variants. European Radiology, 19, 236-244. http://dx.doi.org/10.1007/s00330-008-1126-3

[9] Bordei, P., Sapte, E. and Iliescu, D. (2004) Double Renal Arteries Originating from the Aorta. Surgical and Radiologic Anatomy, 26, 474-479. http://dx.doi.org/10.1007/s00276-004-0272-9

[10] Jinga, V., Dorobat, B., Youssef, S., Radavoi, G., Braticevici, B., et al. (2013) Transarterial Embolization of Renal Vascular Lesions after Percutaneous Nephrolithotomy. Chirurgia (Bucurest), 108, 521-529. 
Scientific Research Publishing (SCIRP) is one of the largest Open Access journal publishers. It is currently publishing more than 200 open access, online, peer-reviewed journals covering a wide range of academic disciplines. SCIRP serves the worldwide academic communities and contributes to the progress and application of science with its publication.

Other selected journals from SCIRP are listed as below. Submit your manuscript to us via either submit@scirp.org or Online Submission Portal.
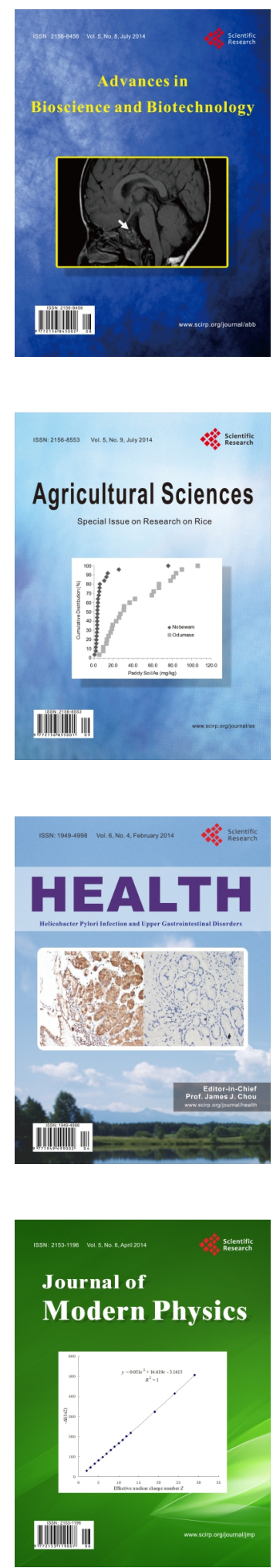
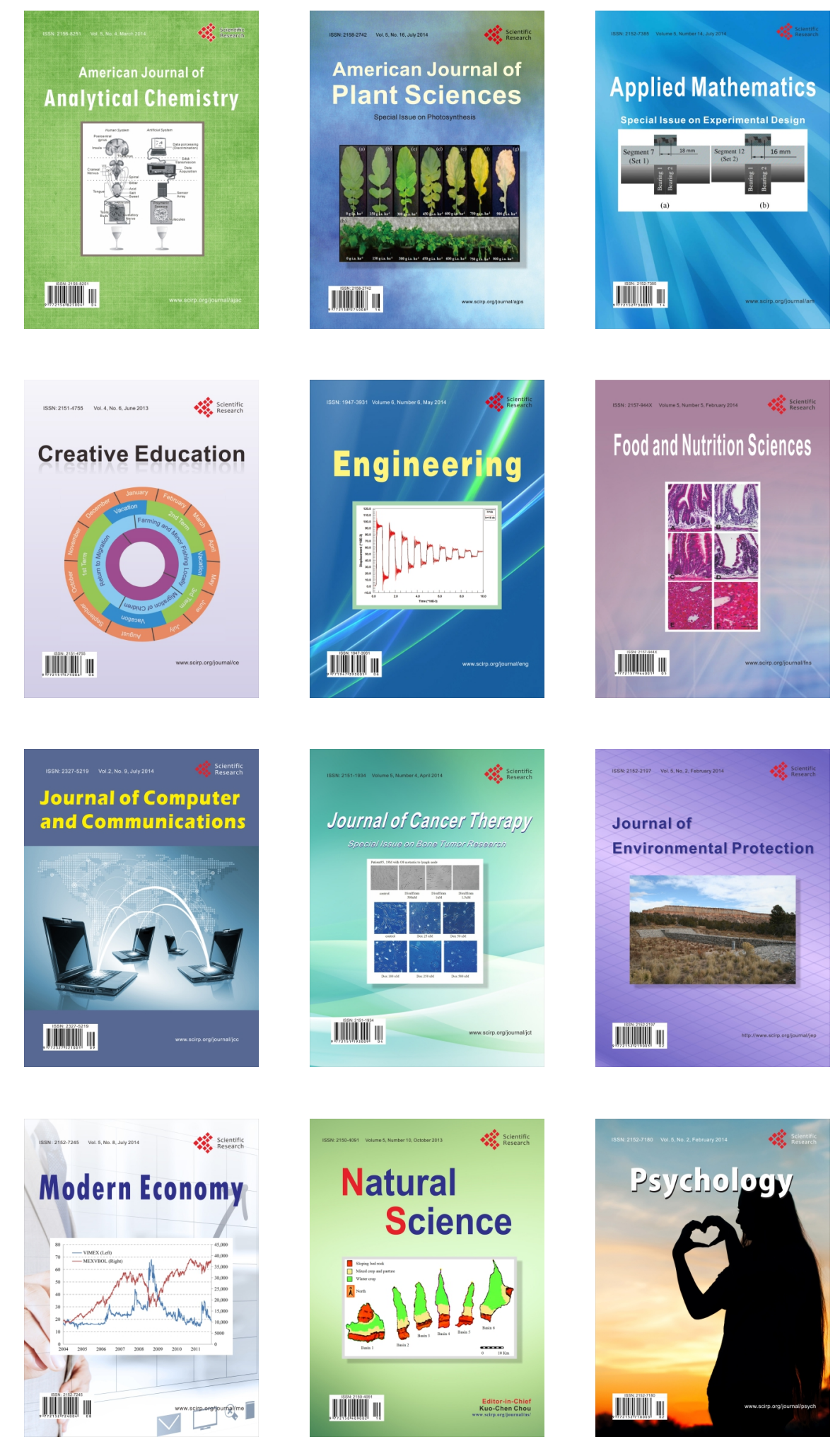